\section{Diode laser transcleral cyclo- photocoagulation for refractory glaucoma: a 1 year follow-up of patients treated using an aggressive protocol}

\author{
Abstract \\ Purpose To prospectively evaluate the \\ intraocular pressure (IOP) lowering ability, \\ retreatment rate, and complications of \\ transcleral Diode laser cyclophotocoagulation \\ using a higher power setting than what is \\ generally recommended. \\ Patients and methods A total of 36 eyes of \\ thirty six patients with refractory glaucoma, \\ and who fitted our inclusion criteria \\ underwent Diode cyclophotocoagulation. The \\ laser power was set at $2250 \mathrm{~mW}$, with a \\ duration of $2000 \mathrm{~ms}$, and a total number of 28 \\ shots for the first treatment and 20 shots for \\ any consequent one. The patients were \\ followed up for 1 year with the following \\ outcomes being analysed: IOP, visual acuity, \\ change in the number of medications, and \\ complications. \\ Results The mean IOP decrease was $53 \%$ \\ $(P<0.05)$, and $72.2 \%$ of the patients \\ maintained an IOP $\leq 21 \mathrm{mmHg}$ for the whole \\ duration of the study The number of \\ medications necessary to control the pressure, \\ significantly dropped from 2.8 to $\mathbf{0 . 8 9}$ \\ $(P<0.05)$, and $25 \%$ of the patients needed the \\ treatment to be repeated only once. \\ In all, $33 \%$ of the patients improved their \\ visual acuity after the treatment, while $22 \%$ \\ worsened, and the rest stayed the same. The \\ most common treatment complications were \\ conjunctival injection and corneal oedema, \\ and these were both transient and reversible. \\ Conclusion The use of the higher power \\ setting of $2250 \mathrm{~mW}$, resulted in a sustained
}

BN Noureddin, W Zein, C Haddad, R Ma'luf and Z Bashshur

lower IOP, less use of medications, less need for retreatment, relative preservation of visual acuity, and only reversible complications. Eye (2006) 20, 329-335. doi:10.1038/sj.eye.6701875; published online 29 April 2005

Keywords: Diode cyclophotocoagulation; intractable glaucoma; intraocular pressure; glaucoma

\section{Introduction}

Our traditional thinking regarding ciliary body ablation has evolved from considering it as a last- resort treatment, reserved only for refractory or end-stage glaucomas, to a more acceptable therapeutic option that is used even as the primary treatment in some cases. This evolution has become possible because of the introduction of safer, simpler, and more easily available modes of ablation; Classically, repeatedly failing glaucoma surgical procedures used to be followed by cyclocryotherapy, which led next to neodynium:YAG, (Nd:YAG) laser cyclodestruction, ${ }^{1}$ and more recently to Diode laser cyclophotocoagulation (DCPC). ${ }^{2,3}$ The weak points of most DCPC studies have been their retrospective design, the absence of a uniform therapeutic approach, and the exclusion of patients with early glaucoma. ${ }^{4}$ Another factor limiting the use of DCPC has been its tendency to lose its therapeutic effect with time, which frequently necessitates multiple treatment sessions to maintain low pressures. ${ }^{2,3}$ Recent studies have shown that the
Department of

Ophthalmology, American University of Beirut, Beirut, Lebanon

Correspondence: BN Noureddin, Department of Ophthalmology, American University of Beirut, PO Box: 11-0236, Bliss Street, Beirut, Lebanon Tel: + 9611350000 ;

Fax: + 9611370837

E-mail: bndean@ aub.edu.lb

Received: 9 December 2004 Accepted: 15 February 2005 Published online: 29 April 2005 
relationship between different power settings and the rates of success, complications, and need for retreatment in DCPC is variable and open to further study., ${ }^{5,6}$ Based on this, and in an effort to decrease the need for retreatment, we have conducted a prospective study, the results of which are reported herewith, using power settings that are higher than what has generally been recommended.

\section{Patients and methods}

The study was designed to prospectively follow-up patients recruited at the Ophthalmology Department of the American University of Beirut in Lebanon, between 1999 and 2002, and fulfilling the criteria for transcleral (DCPC). These criteria included documentation of glaucoma with poor response to maximally tolerated medical therapy, failed previous surgery; unsuitability for or refusal of filtering surgery. Selected patients were assessed for baseline best-corrected Snellen visual acuity, Goldmann tonometry, slit-lamp biomicroscopy, dilated ophthalmoscopy, presence of pain, type and number of glaucoma medications used, and previous systemic and ocular history.

The advantages, risks, and details of the procedure were explained and an informed consent was obtained from all participating patients. None of the patients that were enrolled in the study refused treatment. All were of Middle Eastern ethnic descent, and had brown irides. Transcleral DCPC was performed by the same surgeon (BN), using the Oculight SLX diode laser (IRIS Medical Instruments, Inc., Mountain View, CA, USA), emitting at $810 \mathrm{~nm}$ through a contact probe (G-probe). The majority of the laser procedures - excluding a few paediatric cases that were performed under general anaesthesia - were performed as office procedures under regional anaesthesia, with the retrobulbar injections consisting of a 50:50 mixture of 2\% lignocaine and 0.5\% marcaine. The G-probe was placed at the limbus for patients with preserved ocular anatomy, and the application sites were moved posteriorly by $1.5 \mathrm{~mm}$, for eyes with congenital and developmental glaucoma, and for those with staphylomas. The laser settings consisted of a power of $2250 \mathrm{~mW}$, a pulse duration of $2000 \mathrm{~ms}$, with 26-28 applications on the first treatment, and 20 applications for any subsequent retreatment. The power setting was not increased even if not a single 'pop' was heard during the whole procedure. Similarly, the power setting was not lowered if 'pops' were heard in the early shots, and that is to ensure strict uniformity of the treatment on all patients. Transillumination of the ciliary processes was used in eyes with limbal anatomic changes, and staphylomas. Three hundred and sixty degrees treatment was used in both the primary and retreatment sessions. The 3:00 and 9:00 o'clock positions were always spared to avoid the long ciliary nerves.

Postoperatively, the patients were advised to stop all antiglaucoma medications and were started on prednisolone acetate $1 \%$ eye drops four times daily for 2 weeks. Oral analgesics were prescribed for the first 2 days post-treatment. Patients were examined at 1 week, 1 month, and 6 months after treatment, and as needed thereafter. At each visit, the same pretreatment clinical assessment was repeated.

Successful intraocular pressure (IOP) control was defined as a drop in IOP to $21 \mathrm{mmHg}$ or less, with or without medications. On follow-up visits, glaucoma medications were added as needed to achieve adequate IOP control. Post-treatment pain, discomfort, and complications, if any, were also noted.

Statistical analysis was performed using the Student's $t$-test for paired samples.

\section{Results}

In all, 36 eyes of 36 patients with advanced glaucoma fulfilling the inclusion criteria were recruited, with a male : female ratio of $1.25: 1$. The mean age was $56.9 \pm 21.2$ years (range, $6-80$ years).

The mean follow-up period was $13.69 \pm 5.01$ months (range, 10-36 months). The mean time from glaucoma diagnosis to cyclophotocoagulation was $6.5 \pm 8.1$ years (range, 3 months to 40 years). The patients' clinical characteristics are shown in Table 1. Of note was the fact that aphakic/pseudophakic glaucoma was the most common diagnosis (36\%), followed by advanced primary open-angle glaucoma (19.4\%), and neovascular glaucoma $(16.6 \%)$. Two patients required treatment for pain in their poorly seeing eyes.

The mean pretreatment IOP was $35.8 \pm 9.0 \mathrm{mmHg}$ (range, 22-55 $\mathrm{mmHg}$ ), while the post-treatment mean IOP was $19.08 \pm 5.01 \mathrm{mmHg}$ at the last follow-up visit (Table 2). The IOP profile over the period of follow-up is shown in Table 2. The reduction in IOP was statistically significant at all post-treatment visits $(P<0.05)$. In an effort to further evaluate treatment success, we noted that $27(75 \%)$ of the patients achieved an IOP $\leq 21 \mathrm{mmHg}$ at 6 months, and $26(72.2 \%)$ were able to maintain that level at the final follow-up. Nine patients $(25 \%)$ underwent one repeat diode treatment, over the followup period, and the average number of treatments was $1.25 \pm 0.44$ (range, 1-2).

Table 3 shows the mean number of glaucoma medications drop significantly from a pretreatment mean of $2.8 \pm 1.24$ (range, 1-5) to a post-treatment mean of $0.89 \pm 0.92$ (range, $0-3)(P<0.05)$. Of special interest was the significant drop in the number of patients requiring oral carbonic anhydrase inhibitors, from 19 patients 
Table 1 Clinical characteristics of study patients

\begin{tabular}{|c|c|c|c|c|c|c|}
\hline Patient \# & Age (years) & Sex & Type of glaucoma & Eye & Time since $d x$ (months) & Follow-up (months) \\
\hline 1 & 70 & M & POAG & $\mathrm{R}$ & 120 & 12 \\
\hline 2 & 65 & $\mathrm{~F}$ & Pseudophakic & $\mathrm{L}$ & 4 & 11 \\
\hline 3 & 54 & M & POAG & $\mathrm{R}$ & 36 & 18 \\
\hline 4 & 61 & M & POAG & $\mathrm{R}$ & 60 & 12 \\
\hline 5 & 73 & M & POAG & $\mathrm{R}$ & 48 & 10 \\
\hline 6 & 80 & M & CACG & $\mathrm{R}$ & 300 & 11 \\
\hline 7 & 14 & $\mathrm{~F}$ & Juvenile OAG & $\mathrm{L}$ & 120 & 11 \\
\hline 8 & 68 & $\mathrm{~F}$ & Post PK & $\mathrm{L}$ & 3 & 12 \\
\hline 9 & 68 & M & Malignant & $\mathrm{L}$ & 48 & 13 \\
\hline 10 & 64 & $\mathrm{~F}$ & Pseudophakic & $\mathrm{R}$ & 36 & 36 \\
\hline 11 & 46 & M & Neovascular & $\mathrm{L}$ & 12 & 26 \\
\hline 12 & 24 & $\mathrm{~F}$ & Juvenile OAG & $\mathrm{L}$ & 156 & 12 \\
\hline 13 & 55 & M & Neovascular & $\mathrm{L}$ & 12 & 12 \\
\hline 14 & 66 & $\mathrm{~F}$ & POAG & $\mathrm{L}$ & 144 & 14 \\
\hline 15 & 78 & $\mathrm{~F}$ & Aphakic & $\mathrm{L}$ & 72 & 12 \\
\hline 16 & 18 & $\mathrm{~F}$ & Aphakic & $\mathrm{R}$ & 156 & 12 \\
\hline 17 & 73 & M & Pseudophakic & $\mathrm{L}$ & 60 & 12 \\
\hline 18 & 74 & $\mathrm{~F}$ & Pseudophakic & $\mathrm{R}$ & 6 & 16 \\
\hline 19 & 59 & M & Pseudophakic & $\mathrm{R}$ & 60 & 18 \\
\hline 20 & 70 & $\mathrm{~F}$ & POAG & $\mathrm{L}$ & 240 & 12 \\
\hline 21 & 40 & M & Aphakic & $\mathrm{R}$ & 120 & 22 \\
\hline 22 & 6 & M & Congenital & $\mathrm{R}$ & 72 & 12 \\
\hline 23 & 6 & M & Congenital & $\mathrm{L}$ & 72 & 12 \\
\hline 24 & 67 & M & Aphakic & $\mathrm{R}$ & 60 & 13 \\
\hline 25 & 73 & $\mathrm{~F}$ & Neovascular & $\mathrm{R}$ & 24 & 13 \\
\hline 26 & 22 & M & Post PK & $\mathrm{R}$ & 12 & 11 \\
\hline 27 & 63 & M & Pseudoexfoliative & $\mathrm{R}$ & 36 & 11 \\
\hline 28 & 75 & M & Neovascular & $\mathrm{R}$ & 12 & 12 \\
\hline 29 & 80 & M & CACG & $\mathrm{L}$ & 36 & 11 \\
\hline 30 & 51 & M & Pseudophakic & $\mathrm{R}$ & 480 & 12 \\
\hline 31 & 64 & $\mathrm{~F}$ & Neovascular & $\mathrm{R}$ & 3 & 13 \\
\hline 32 & 58 & $\mathrm{~F}$ & Aphakic & $\mathrm{R}$ & 24 & 12 \\
\hline 33 & 58 & $\mathrm{~F}$ & Aphakic & $\mathrm{L}$ & 24 & 12 \\
\hline 34 & 76 & M & POAG & $\mathrm{R}$ & 120 & 11 \\
\hline 35 & 60 & $\mathrm{~F}$ & Neovascular & $\mathrm{L}$ & 3 & 13 \\
\hline 36 & 70 & $\mathrm{~F}$ & Pseudophakic & $\mathrm{L}$ & 6 & 11 \\
\hline Mean & 56.92 & $16 \mathrm{~F}$ & & $16 \mathrm{~L}$ & 77.69 & 13.69 \\
\hline SD & 21.21 & $20 \mathrm{M}$ & & $20 \mathrm{R}$ & 97.08 & 5.01 \\
\hline
\end{tabular}

$\mathrm{dx}=$ diagnosis.

before treatment to only three following treatment $(P<0.05)$.

Preoperative visual acuity ranged from $20 / 50$ to light perception (LP), while the postoperative range was 20/40 to LP. With regard to the final change in visual acuity, 12 (33\%) of the patients improved at the last follow-up visit, $16(44 \%)$ maintained the same visual acuity, and eight (22\%) worsened. The breakdown of change in vision by Snellen acuity lines is shown in Table 4.

Complications are shown in Table 5, and they mainly include conjunctival injection and corneal edema, in the majority of patients on the 1st day, and 1st week after treatment. Less frequent and reversible complications were hyphaema, anterior chamber fibrinoid reaction, sterile hypopyon, and vitreous haemorrhage. The patients manifesting haemorrhagic complications (hyphaema and vitreous haemorrhage) were noted to be predominantly suffering from neovascular glaucoma. No cases of postpenetrating keratoplasty graft failure were noted. One patient $(2.7 \%)$ with advanced age and diabetic neovascular glaucoma went into relative hypotony, but still maintained his LP vision throughout the follow-up period.

\section{Discussion}

Diode laser transcleral cyclophotocoagulaion (DCPC) has exhibited better efficacy, safety, reliability, and convenience compared to previous methods of ciliary body ablation for the treatment of the difficult 
Table 2 Pre- and postprocedure IOP $(\mathrm{mmHg})$, and the number of treatments

\begin{tabular}{|c|c|c|c|c|c|c|c|}
\hline Patient \# & Pre tx IOP (mmHg) & IOP day 1 & IOP week1 & IOP 6 months & IOP Last FU & FU time (months) & \# of txs \\
\hline 1 & 27 & 9 & 14 & 16 & 15 & 12 & 1 \\
\hline 2 & 45 & 18 & 19 & 17 & 18 & 11 & 1 \\
\hline 3 & 30 & 16 & 17 & 18 & 17 & 18 & 1 \\
\hline 4 & 31 & 16 & 14 & 18 & 21 & 12 & 1 \\
\hline 5 & 32 & 22 & 16 & 15 & 13 & 10 & 1 \\
\hline 6 & 22 & 26 & 24 & 17 & 9 & 11 & 2 \\
\hline 7 & 28 & 24 & 28 & 22 & 18 & 11 & 1 \\
\hline 8 & 42 & 33 & 36 & 24 & 7 & 12 & 2 \\
\hline 9 & 26 & 18 & 7 & 10 & 14 & 13 & 1 \\
\hline 10 & 40 & 20 & 18 & 20 & 16 & 36 & 1 \\
\hline 11 & 40 & 38 & 48 & 35 & 36 & 26 & 2 \\
\hline 12 & 40 & 22 & 28 & 24 & 22 & 12 & 1 \\
\hline 13 & 36 & 28 & 22 & 24 & 26 & 12 & 1 \\
\hline 14 & 50 & 40 & 26 & 20 & 28 & 14 & 1 \\
\hline 15 & 25 & 20 & 14 & 15 & 17 & 12 & 1 \\
\hline 16 & 32 & 11 & 13 & 17 & 22 & 12 & 1 \\
\hline 17 & 48 & 14 & 12 & 15 & 14 & 12 & 1 \\
\hline 18 & 22 & 7 & 16 & 15 & 12 & 16 & 1 \\
\hline 19 & 32 & 9 & 29 & 18 & 6 & 18 & 1 \\
\hline 20 & 34 & 18 & 18 & 18 & 20 & 12 & 1 \\
\hline 21 & 40 & 19 & 48 & 20 & 14 & 22 & 2 \\
\hline 22 & 26 & 10 & 14 & 16 & 15 & 12 & 1 \\
\hline 23 & 26 & 18 & 14 & 17 & 19 & 12 & 1 \\
\hline 24 & 26 & 30 & 38 & 20 & 16 & 13 & 2 \\
\hline 25 & 34 & 21 & 9 & 10 & 2 & 13 & 1 \\
\hline 26 & 50 & 32 & 34 & 30 & 35 & 11 & 2 \\
\hline 27 & 42 & 28 & 32 & 30 & 36 & 11 & 1 \\
\hline 28 & 44 & 24 & 26 & 28 & 32 & 12 & 1 \\
\hline 29 & 33 & 7 & 10 & 8 & 10 & 11 & 1 \\
\hline 30 & 49 & 26 & 30 & 34 & 46 & 12 & 2 \\
\hline 31 & 55 & 30 & 38 & 18 & 14 & 13 & 2 \\
\hline 32 & 32 & 14 & 10 & 17 & 22 & 12 & 1 \\
\hline 33 & 26 & 19 & 20 & 19 & 20 & 12 & 1 \\
\hline 34 & 40 & 18 & 18 & 17 & 18 & 11 & 1 \\
\hline 35 & 50 & 30 & 26 & 19 & 16 & 13 & 2 \\
\hline 36 & 35 & 18 & 20 & 16 & 21 & 11 & 1 \\
\hline Mean & 35.83 & 20.92 & 22.39 & 19.36 & 19.08 & 13.69 & 1.25 \\
\hline SD & 9.04 & 8.35 & 10.53 & 6.07 & 9.16 & 5.01 & 0.44 \\
\hline$P$-value & & $<0.05$ & $<0.05$ & $<0.05$ & $<0.05$ & & \\
\hline
\end{tabular}

$\mathrm{tx}=$ treatment; $\mathrm{FU}=$ follow-up.

glaucomas. The combination of several advantages has encouraged several groups to study the various aspects of this treatment. ${ }^{2-16}$ Some studies have made use of these facts to attempt even primary treatment of high-risk patients, ${ }^{3,18}$ and to compare results of cyclophotocoagulation to better-established treatment options, such as filtering surgery, and

drainage implants. Unfortunately, most of these studies were retrospective, with significant variability in the energy settings and in the number of applications making comparison and inference quite difficult. ${ }^{5,6}$

In all, 36 patients with intractable glaucoma and who fitted our inclusion criteria, underwent DCPC using a primary power setting that is higher than what has been published and recommended. Our results show that the higher power setting of $2250 \mathrm{~mW}$ (as opposed to the generally recommended starting level of $1500 \mathrm{~mW}$ that is increased until a 'pop' is heard) is associated with a higher success rate, without jeopardizing the safety of DCPC. Our choice of this setting is based on studies of human cadaver eyes, where the higher end of optimum energy for DCPC was found to be 3-4.5 J per laser spot, ${ }^{19}$ as well as on histopathologic examination of treated eyes. ${ }^{20,21}$ Secondly, this higher power setting has already proved to be safe when used previously in retreating cases that were not controlled with the initial $1500 \mathrm{~mW}$ treatment. 
Table 3 Pre- and postprocedure number and type of medications

\begin{tabular}{lcc}
\hline Type of medication & Pre tx & Post tx \\
\hline B-blockers & 17 & 11 \\
Topical CAI & 7 & 1 \\
Fixed combination timolol/dorzolamide & 15 & 10 \\
Brimonidine & 16 & 2 \\
Prostaglandins & 19 & 5 \\
Miotics & 8 & 0 \\
Systemic CAI & 19 & 3 \\
Mean \# of total medications & 2.81 & 0.89 \\
SD of total medications & 1.24 & 0.92 \\
\hline
\end{tabular}

$\mathrm{tx}=$ treatment; $\mathrm{CAI}=$ carbonic anhydrase inhibitors

Table 4 Pre- and postprocedure snellen visual acuity

\begin{tabular}{|c|c|c|c|}
\hline Patient \# & Preop VA & $V A 1$ week post $t x$ & Final VA \\
\hline 1 & $\mathrm{HM}$ & $\mathrm{HM}$ & CFNF \\
\hline 2 & $20 / 70$ & $20 / 100$ & $20 / 50$ \\
\hline 3 & CF $1.0 \mathrm{~m}$ & CF $0.5 \mathrm{~m}$ & CF $1.0 \mathrm{~m}$ \\
\hline 4 & LP & LP & LP \\
\hline 5 & $20 / 200$ & $20 / 400$ & $20 / 100$ \\
\hline 6 & CF $4.0 \mathrm{~m}$ & CF 3.0M & CF $6.0 \mathrm{~m}$ \\
\hline 7 & 20/100 & $20 / 100$ & $20 / 40$ \\
\hline 8 & $20 / 200$ & $20 / 100$ & $20 / 70$ \\
\hline 9 & $20 / 200$ & $20 / 400$ & $20 / 200$ \\
\hline 10 & CF $2.0 \mathrm{~m}$ & CF $1.0 \mathrm{~m}$ & CF $1.0 \mathrm{~m}$ \\
\hline 11 & LP & LP & LP \\
\hline 12 & LP & LP & LP \\
\hline 13 & $\mathrm{HM}$ & $\mathrm{HM}$ & $\mathrm{HM}$ \\
\hline 14 & CF $4.0 \mathrm{~m}$ & CF $4.0 \mathrm{~m}$ & CF $4.0 \mathrm{~m}$ \\
\hline 15 & CF $2.0 \mathrm{~m}$ & CF $1.0 \mathrm{~m}$ & CF $3.0 \mathrm{~m}$ \\
\hline 16 & $20 / 50$ & $20 / 100$ & $20 / 70$ \\
\hline 17 & CF $1.0 \mathrm{~m}$ & CF $1.0 \mathrm{~m}$ & CF $2.0 \mathrm{~m}$ \\
\hline 18 & CF $0.5 \mathrm{~m}$ & HM & CF $0.5 \mathrm{~m}$ \\
\hline 19 & $20 / 100$ & $20 / 400$ & $20 / 400$ \\
\hline 20 & LP & LP & LP \\
\hline 21 & $20 / 70$ & $20 / 400$ & $20 / 70$ \\
\hline 22 & CF $2.0 \mathrm{~m}$ & CF $2.0 \mathrm{~m}$ & CF $3.0 \mathrm{~m}$ \\
\hline 23 & CF $2.0 \mathrm{~m}$ & CF $2.0 \mathrm{~m}$ & CF $4.0 \mathrm{~m}$ \\
\hline 24 & CF $3.0 \mathrm{~m}$ & CF $0.5 \mathrm{~m}$ & CF $2.0 \mathrm{~m}$ \\
\hline 25 & CF $0.5 \mathrm{~m}$ & CFNF & LP \\
\hline 26 & $\mathrm{HM}$ & $\mathrm{HM}$ & $\mathrm{HM}$ \\
\hline 27 & LP & LP & LP \\
\hline 28 & LP & LP & LP \\
\hline 29 & CF $4.0 \mathrm{~m}$ & CF $1.0 \mathrm{~m}$ & CF $6.0 \mathrm{~m}$ \\
\hline 30 & LP & LP & LP \\
\hline 31 & LP & LP & LP \\
\hline 32 & $20 / 100$ & CF $6.0 \mathrm{~m}$ & CF $5.0 \mathrm{~m}$ \\
\hline 33 & $20 / 70$ & $20 / 100$ & $20 / 200$ \\
\hline 34 & LP & LP & LP \\
\hline 35 & CF $1.0 \mathrm{~m}$ & CF 3.0M & CF $6.0 \mathrm{~m}$ \\
\hline 36 & $\mathrm{HM}$ & HM & LP \\
\hline
\end{tabular}

$\mathrm{t} x=$ treatment $\mathrm{HM}=$ hand motion; $\mathrm{CF}=$ counting fingers; $\mathrm{LP}=$ light perception; $\mathrm{CFNF}=$ Counting fingers near face.

Thirdly, we seem to have arrived at this higher setting after studying several parameters in an attempt to come up with a regimen that has low retreatment rates. An
Table 5 Procedure complications

\begin{tabular}{lcc}
\hline Complication & Number of patients & Percentage (\%) \\
\hline Conjunctival injection & 5 & \\
$\quad$ Mild & 23 & 13.80 \\
$\quad$ Moderate & 8 & 63.80 \\
$\quad$ Severe & & 22.20 \\
Corneal oedema & 16 & \\
$\quad$ Mild/Moderate & 10 & 44.40 \\
$\quad$ Severe & 7 & 27.70 \\
Fibrinoid reaction & 3 & 19.40 \\
Sterile hypopyon & 2 & 8.30 \\
Hyphaema & 1 & 5.50 \\
Vitreous haemorrhage & 1 & 2.70 \\
Air in anterior chamber & 1 & 2.70 \\
Hypotony & & 2.70 \\
\hline
\end{tabular}

audible pop was not a priority in our setting, as several studies had failed to show any correlation between the presence of pops, and a definite therapeutic response. ${ }^{4,22}$

The results of our study reveal a drop of IOP of about $53 \%$, which compares favourably with the 30-50\% range that has been reported in the literature. ${ }^{5,6,14}$ The percentage of patients achieving an IOP of $21 \mathrm{mmHg}$, or less was $75 \%$ at 6 months, and $72.2 \%$ at the last follow-up; this is also in agreement with the figures of 38-95\% in the literature. ${ }^{5,6}$ Most importantly, is the maintenance of the pressure lowering effect over the mean follow-up of 14 months, without the need for multiple retreatments. A main shortcoming of some of the published series is the relatively short follow-up period; ${ }^{6}$ a problem that we have attempted to address in the current study.

Only $25 \%$ of our patients needed one retreatment to maintain the required effect, while this figure goes up to $49 \%$ in the published studies..$^{2,3,11-13,15}$ We speculate that a safe power setting resulting in the required pressure lowering with a low rate of retreatments, cannot be but associated with a lower incidence of hypotony in the long run. Only one patient $(2.7 \%)$ developed relative hypotony in this study, compared to a range of $1-2 \%$ in the literature. ${ }^{2,14}$ It is conceivable that multiple treatment sessions be associated with a higher risk of hypotony, considering their cumulative destructive effect on the ciliary epithelium.

The significant reduction in the number of glaucoma medications from a mean of 2.81 to $0.89(P<0.05)$ was of major interest. This was extremely helpful in maintaining adequate target pressures for most of the patients, while avoiding the ocular and systemic side effects of these medications. As an example, only three patients required oral carbonic anhydrase inhibitors post-treatment compared to 19 pretreatment $(P<0.05)$. Achieving 
optimal pressure control with little or no medical treatment is a vital economic issue in developing countries, where the prohibitive cost of life-long medical treatment poses a major burden on the limited resources of the patient himself, and that of his health authority or government.

In $25 \%$ of the study patients vision improved by 2 or more Snellen lines; $13.8 \%$ suffered a comparable loss, while the rest remained unchanged. These are promising figures when compared to those in other studies, ${ }^{14,17}$ and this may be partly related to the higher percentage of patients with relatively good visual acuity enrolled in this study. Only few painful eyes with very little vision were included.

Mild-to-severe conjunctival injection was a very constant feature in the vast majority of patients (Table 5). However, this was transient and responded well to topical prednisolone. Another common finding was corneal oedema. The latter was usually mild and also short lived. These two complications are probably more common than in other studies, ${ }^{3}$ and this might be attributed to the higher power setting, as observed also by Chang et al. ${ }^{6}$ The rest of the complications were rare and all reversible, except for the previously mentioned case of relative hypotony.

The results of our study would be more conclusive if the number of treated patients were larger. However, this number still compares well with most of the published series, and to reset the balance is the relative long mean follow-up of 14 months, plus the prospective design of the study. The distribution of diagnosis of the usual intractable glaucomas is also well represented among our patients.

Another limitation of our study is the absence of randomized controls. The known progressively deteriorating natural course of eyes with intractable glaucoma ethically prevented us from silently observing a matched control group of patients. Secondly, using the standard $1500 \mathrm{~mW}$ power setting in a control group would not have been ethical either, as we already know that such a power setting is less likely to establish adequate long-term results without the need for retreatment. $^{6}$

In conclusion, we believe that DCPC with the higher power setting is still a safe and reliable method of treating advanced glaucoma. The pressure lowering seems to be well maintained, with less medications, with a lesser need for retreatment, and with minimal complications, while still preserving visual acuity to a good extent. Many aspects of this treatment warrant further investigation, including randomized controlled clinical studies, the combination of different therapies, and the establishment of optimum and more standardized energy settings.

\section{References}

1 Noureddin BN, Wilson-Holt N, Lavin M, Jeffrey M, Hitchings RA. Advanced uncontrolled glaucoma: Nd:YAG cyclophotocoagulation or tube surgery. Ophthalmology 1992; 99: 430-436.

2 Bloom P, Tsai J, Sharma K, Miller M, Rice N, Hitchings RA et al. Trans-scleral diode laser cyclophotocoagulation in the treatment of advanced refractory glaucoma. Ophthalmology 1997; 104: 1508-1520.

3 Kramp K, Vick H, Guthoff R. Transscleral diode laser contact cyclophotocoagulation in the treatment of different glaucomas, also as primary surgery. Graefes Arch Clin Exp Ophthalmol 2002; 240: 698-703.

4 Pastor S, Singh K, Lee D, Juzych M, Lin S, Netland P et al. Cyclophotocoagulation: a report by the American Academy of Ophthalmology. Ophthalmology 2001; 108: 2130-2138.

5 Hauber F, Scherer W. Influence of total energy delivery on success rate after contact diode laser transscleral cyclophotocoagulation: a retrospective case review and meta-analysis. J Glaucoma 2002; 11: 329-333.

6 Chang SH, Chen YC, Li CY, Wu SC. Contact diode laser transcleral cyclophotocoagulation for refractory glaucoma: comparison of two treatment protocols. Can J Ophthalmol 2004; 39: 511-516.

7 Brancato R, Carrassa RG, Bettin P, Firoi M, Trabucchi G. Contact transscleral cyclophotocoagulation with diode laser in refractory glaucoma. Eur J Ophthalmol 1995; 5: 32-39.

8 Mistelberger A, Liebmann J, Tschiderer H, Ritch R, Ruckhofer J, Grabner G. Diode laser transscleral cyclophotocoagulation for refractory glaucoma. J Glaucoma 2001; 10: 288-293.

9 Gupta N, Weinreb R. Diode laser transscleral cyclophotocoagulation. J Glaucoma 1997; 6: 426-429.

10 Wong E, Chew P, Chee C, Wong JS. Diode laser contact transscleral cyclophotocoagulation for refractory glaucoma in asian patients. Am J Ophthalmol 1997; 124: 797-804.

11 Lai J, Tham C, Chan J, Lam D. Diode laser transscleral cyclophotocoagulation in the treatment of chronic angleclosure glaucoma: a preliminary study. J Glaucoma 2003; 12: 360-364.

12 Izgi B, Demirci H, Demirci Y, Turker G. Diode laser cyclophotocoagulation in refractory glaucoma: comparison between pediatric and adult glaucomas. Ophthalmic Surg Lasers 2001; 32: 100-107.

13 Schlote T, Derse M, Rassmann K, Nicaeus T, Dietz K, Thiel HJ. Efficacy and safety of contact transscleral diode laser cyclophotocoagulation for advanced glaucoma. J Glaucoma 2001; 10: 294-301.

14 Yap-Veloso M, Simmons R, Echelman D, Gonzales T, Veira W, Simmons R. Intraocular pressure control after contact transscleral diode cyclophotocoagulation in eyes with intractable glaucoma. J Glaucoma 1998; 7: 319-328.

15 Hennis HL, Stewart WC. Semiconductor diode laser transscleral cyclophotocoagulation in patients with glaucoma. Am J Ophthalmol 1992; 113: 81-85.

16 Hawkins TA, Stewart WC. One-year results of semiconductor transscleral cyclophotocoagulation in patients with glaucoma. Arch Ophthalmol 1993; 111: 488-491.

17 Kosoko O, Gaasterland DE, Pollack IP, Enger CL. Long-term outcome of initial ciliary ablation with contact diode laser transscleral cyclophotocoagulation for severe glaucoma. Ophthalmology 1996; 103: 1294-1302. 
18 Sengupta R, Austin M, Morgan J. Treatment of aqueous misdirection by trans-scleral diode laser photocoagulation. Eye 2000; 14: 808-810.

19 Schuman JS, Noecker RJ, Puliafito CA, Jacobson JJ, Shepps GJ, Wang N. Energy levels and probe placement in contact transscleral semiconductor diode laser

cyclophotocoagulation in human cadaver eyes. Arch Ophthalmol 1991; 109: 1534-1538.
20 McKelvie P, Walland M. Pathology of cyclodiode laser: a series of nine enucleated eyes. Br J Ophthalmol 2002; 86: 381-386.

21 Walland M, McKelvie P. Diode laser cyclophotocoagulation: histopathology in two cases of clinical failure. Ophthalmic Surg Lasers 1998; 29: 852-856.

22 Rebolleda G, Munoz F, Murube J. Audible pops during cyclodiode procedures. J Glaucoma 1999; 8: 177-183. 